\title{
Joint Analysis of Quantitative Trait Loci for Clinical Mastitis and Somatic Cell Score on Five Chromosomes in Three Nordic Dairy Cattle Breeds
}

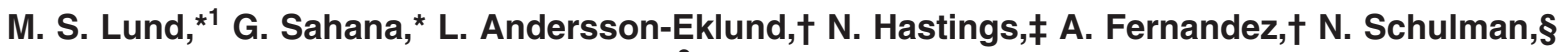 \\ B. Thomsen, ${ }^{*}$ S. Viitala, $§$ J. L. Williams, $\ddagger^{2}$ A. Sabry, ${ }^{*}$ H. Viinalass,\# and J. Vilkki§ \\ *Department of Genetics and Biotechnology, Faculty of Agricultural Sciences, University of Aarhus, Research Centre Foulum, \\ 8830 Tjele, Denmark \\ †Department of Animal Breeding and Genetics, Swedish University of Agricultural Sciences, S-750 07 Uppsala, Sweden \\ ¥Roslin Institute, Roslin, Midlothian, EH25 9PS, United Kingdom \\ §MTT, Agrifood Research Finland, Biotechnology and Food Research, FIN-31600 Jokioinen, Finland \\ \#Institute of Veterinary Medicine and Animal Sciences, EMU, Kreutzwaldi 64, Tartu 51014, Estonia
}

\section{ABSTRACT}

Five chromosomes were selected for joint quantitative trait loci (QTL) analyses for clinical mastitis (CM) and somatic cell score (SCS) in 3 breeds: Finnish Ayrshire (FA), Swedish Red and White (SRB), and Danish Red (DR). In total, 19 grandsires and 672 sons in FA, 19 grandsires and 499 sons in SRB, and 8 grandsires and 258 sons in DR were used in the study. These individuals were genotyped with the 61 microsatellite markers used in any of the previous QTL scans on the selected chromosomes. Within-family QTL analyses based on linear regression models were carried out for CM and SCS to identify the segregating sires for each region. On the segregating families, joint single-trait and 2-trait analyses were performed using variance components models. The analyses confirmed that QTL affecting CM or SCS, or both, segregate on Bos taurus autosomes (BTA) 9, 11, 14, and 18, whereas a QTL on BTA29 could not be confirmed. Our results indicate that there may be at least 2 linked QTL on BTA9, one that primarily affects $\mathrm{CM}$ and a second that primarily affects SCS. On chromosomes BTA11, 14, and 18, the joint analyses were only significant for SCS.

Key words: quantitative trait loci, mastitis, somatic cell score, dairy cattle

\section{INTRODUCTION}

Mastitis is the most important health problem affecting dairy cattle. The incidence of clinical mastitis (CM) has increased over time in many countries (Rupp and Boichard, 2003). This trend is a response correlated

Received March 8, 2007.

Accepted June 27, 2007.

${ }^{1}$ Corresponding author: Mogens.Lund@agrsci.dk

${ }^{2}$ Present address: Parco Tecnologico Padano, via Einstein, Polo Universitario, Lodi 26900, Italy. with efficient selection for productivity and its unfavorable genetic correlation with mastitis susceptibility (Strandberg and Shook, 1989; Pösö and Mäntysaari, 1996; Lund et al., 1999; Carlén et al., 2004). Therefore, mastitis resistance is an important breeding objective. However, making genetic progress by traditional breeding is difficult because mastitis incidence is lowly heritable (Heringstad et al., 2000; Hansen et al., 2002; Carlén et al., 2004), difficult to record, and antagonistically correlated genetically with production traits (Pösö and Mäntysaari, 1996; Lund et al., 1999; Carlén et al., 2004). Mastitis resistance is therefore a prime candidate for marker-assisted selection. Recent genomic research is yielding new knowledge about the bovine genome and will facilitate identification of genes that could be used in breeding programs to improve certain traits. The identification of major loci affecting resistance to mastitis and the application of genotype-based marker-assisted selection to breed for improved mastitis resistance would give the dairy industry new opportunities for genetic improvement of mastitis resistance and thus improve the health status in dairy cattle populations.

Mapping of QTL in livestock using existing population structures is restricted to the traits that are recorded in the breeding schemes. Most studies to identify QTL for mastitis resistance have used SCS as an indicator trait for subclinical mastitis as well as CM, which is the main objective for improvement but is often not recorded. Breeding schemes often use SCS because it shows a moderate to high genetic correlation to $\mathrm{CM}$ (Lund et al., 1999; Carlén et al., 2004; Heringstad et al., 2006) and is easier to record. However, it is unknown whether QTL that have been identified for SCS also affect CM. The Nordic countries have traditionally given special attention to health traits in dairy cattle breeding. This has been facilitated by the nationwide recording of all traits of major importance, including diseases, which have not been systematically recorded 
in other countries. One of the key elements in the scheme is an individual health card for each cow, which is updated each time a veterinarian treats the animal. The system was first applied on a national basis in Norway in 1975 and later adopted in Finland (1982), Sweden (1984), and Denmark (1986). Because of this extensive recording, the Nordic countries provide a unique resource for mapping of loci affecting key functional traits especially CM in dairy cattle.

Preliminary analyses have shown that putative QTL for mastitis resistance segregate in current Nordic breeding populations (Klungland et al., 2001; Holmberg and Andersson-Eklund, 2004; Schulman et al., 2004; our unpublished data). The QTL affecting CM or SCS were found segregating on the same chromosomes in more than one population. These QTL were reported based on within-breed and within-country analyses. It was not possible to compare the results across different breeds or countries because of differences in markers and linkage maps. These Nordic breeds have both historic and recent genetic connections. Therefore, joint analysis offers the opportunity to extract additional information from the data. To reach sufficient statistical power to confirm mapped QTL, more segregating families were required than were available within the individual country populations. It was also necessary to verify the existence of the suggestive QTL in other populations. Confidence for the existence of the QTL as well as refining the position can be obtained by consistent results between within-breed analyses and combined breed analyses.

The original data suggested that some of the chromosomes were harboring QTL affecting both CM and SCS. Multiple-trait analysis of these chromosomes could be applied to distinguish between close linkage of 2 QTL and pleiotropic effects of 1 QTL for the 2 traits. When a QTL has a pleiotropic effect on 2 or more traits, a joint analysis involving both traits may result in greater statistical power to detect the QTL, and more precision to estimate its position (Jiang and Zeng, 1995; Knott and Haley, 2000; Sørensen et al., 2003). This is particularly true if a second correlated trait with higher heritability is used to map QTL for a trait with low heritability (Sørensen et al., 2003). Multiple-trait QTL mapping allows decomposition of variances and covariances into polygenic and QTL components, which is relevant for selection purposes. This study was planned to undertake the joint analysis of 5 chromosomes affecting CM or SCS from 3 populations of dairy cattle. The overall objective of the study was to combine separate, suggestive linkage mapping results from 3 Nordic studies (Finnish, Swedish, and Danish) into a single, multiplepopulation analysis.

\section{MATERIALS AND METHODS}

The following 5 steps were used to join the 3 Nordic studies efficiently: 1) selection of chromosomes where joint analyses would be most likely to increase accuracy; 2) genotyping additional families with a common marker set; 3) identifying those families that were likely to be segregating for QTL on the chromosomes selected in 1 ; 4) genotyping the segregating families with 5- to 10-cM marker spacing for the QTL regions; and 5) joint statistical analysis of the 3 breeds to confirm results and refine intervals.

\section{Data}

Selection of Chromosomes for Joint Study. Five chromosomes were identified based on the previous QTL-mapping studies of 46 half-sib families from Finnish Ayrshire (FA), Swedish Red and White (SRB), and Danish Red (DR) (Holmberg and Andersson-Eklund, 2004; our unpublished data; Schulman et al., 2004). In the identification of chromosomal areas harboring mastitis related QTL, the following criteria were used: 1) the region had significant QTL previously identified in at least 2 populations and 2) the region affected both $\mathrm{CM}$ and SCS. The 5 chromosomes selected were Bos taurus autosomes (BTA) 9, 11, 14, 18, and 29. These chromosomes were selected because BTA9 contained a QTL for CM or SCS, which was segregating in DR, FA, and SRB; BTA11 contained QTL for SCS in FA and SRB and for CM in FA; BTA14 had a QTL affecting CM and SCS in FA; BTA18 had a QTL for CM and SCS in FA; and BTA29 had a QTL affecting SCS QTL in DR and FA.

Animal Material. Nineteen grandsires and 672 sons in FA, 19 grandsires and 499 sons in SRB, and 8 grandsires and 258 sons in DR were used in the study. These individuals were genotyped with the microsatellite markers used in the previous QTL scans on the selected chromosomes. Within-family QTL analyses based on linear regression models were carried out for CM and SCS to identify the segregating sires for each region. A family was considered to be segregating for one of the traits when the chromosome-wide significance was $>90 \%$. This liberal threshold was used to ensure that sufficient families were included in the combined analysis. From 15 to 21 families per chromosome were identified to be segregating for one of the mastitisrelated QTL.

Phenotypic Data. Phenotypes were derived from the models used to produce breeding values in the individual countries. Definitions differed slightly between countries. The trait CM was defined as a binary trait, based on whether the cow had at least one veterinary treatment for mastitis in a predefined period of risk. 
Table 1. Distribution of the markers across the 5 chromosomes

\begin{tabular}{|c|c|c|}
\hline $\begin{array}{l}\text { Bos taurus } \\
\text { autosome }\end{array}$ & $\begin{array}{l}\text { Markers } \\
\quad(\mathrm{n})\end{array}$ & Markers (position in cM) \\
\hline 9 & 17 & $\begin{array}{l}\text { CSSM025(41.5) TGLA261(44.6) UWCA9(44.9) BM4204(49.8) BMS1909(54.3) BMS1290(59.0) TGLA73(71.4) } \\
\text { BMS2753(73.1) BMS1724(74.1) BMS2251(80.8) INRA144(84.3) bms2819(84.4) BM4208(84.6) } \\
\text { BMS2063(89.3) cssm56(95.0) BMS1943(96.7) BMS1967(102.5) }\end{array}$ \\
\hline 11 & 15 & $\begin{array}{l}\text { HELMTT43(0.0) BM716(5.5) BMS2569(7.4) BM2818(18.2) INRA177(24.3) RM96(32.6) INRA131(38.3) } \\
\text { BM7169(45.5) BMS1716(48.5) BM6445(54.9) HELMTT44(62.7) TGLA58(63.3) HUJV174(85.4) TGLA436(98.5) } \\
\text { HEL13(114.5) }\end{array}$ \\
\hline 14 & 8 & $\begin{array}{l}\text { ILSTS039(0.0) BMS1747(14.6) ILSTS011(18.7) RM180(26.7) BMS1941(36.0) RM011(39.2) BM302(44.0) } \\
\text { BMS740(49.5) }\end{array}$ \\
\hline 29 & 20 & $\begin{array}{l}\text { BM4602(0.0) BMS1857(0.9) BMS1244(1.5) ILSTS057(5.4) BMS764(9.7) BMC8012(11.0) BMS1787(18.5) } \\
\text { RM179(22.4) RM040(23.3) RM044(23.31) BMS1600(28.4) MB107(39.9) OARHH22(41.5) BMC3224(43.6) } \\
\text { BL1100(46.6) RME33(50.1) BMC1206(57.5) BMC6004(57.9) BMS1948(61.6) ILSTS081(65.0) }\end{array}$ \\
\hline
\end{tabular}

The periods of risk were $10 \mathrm{~d}$ before calving to $50 \mathrm{~d}$ after calving in DR and $7 \mathrm{~d}$ before to $150 \mathrm{~d}$ after calving in FA and SRB. Somatic cell score was defined as the mean of $\log _{10}$ transformed SCC values (in $1,000 / \mathrm{mL}$ ) obtained from the milk recording scheme. The mean was taken over the period 10 to $180 \mathrm{~d}$ after calving in $\mathrm{DR}, 10$ to $150 \mathrm{~d}$ after calving in FA, and 10 to $180 \mathrm{~d}$ after calving in SRB. Before joint analyses, the phenotypes were standardized to the same mean and variation.

Genetic Markers in Joint Analyses. In total, 61 markers were used (Table 1). For BTA9, 17 microsatellite markers were used in 16 grandsire families (10 SRB, 4 FA, and 2 DR) including 478 bulls. Twenty-one half-sib families (8 SRB, $10 \mathrm{FA}$, and $3 \mathrm{DR}$ ) including 719 bulls were genotyped for 15 markers on BTA11. Eight markers were genotyped for 16 families (6 SRB, 7 FA, and 3 DR) with 517 sons on BTA14. On BTA18, 16 microsatellite markers were genotyped in 17 families (10 SRB, $6 \mathrm{FA}$, and one DR) including 542 bulls and on BTA29, 20 markers were genotyped in 15 families (8 SRB, $3 \mathrm{FA}$, and $4 \mathrm{DR}$ ) with a total of 474 bulls.

\section{Statistical Methods}

The linkage maps were estimated using CRI-MAP (Green et al., 1990). The QTL analyses were performed with the new marker maps produced. The QTL analysis procedure was as follows. First, a single-trait variance component model across families was used for SCS and CM. Second, 4 different 2-trait models were used: a pleiotropic model fitting a single QTL affecting SCS and CM (MT $\mathbf{P})$; a linked-QTL model in which 2 linked QTL were fit, one affecting SCS and the other affecting CM $\left(\mathbf{M T}_{\mathbf{L}}\right)$; and a 2-trait model with the 1 QTL only affecting CM (MT $\mathbf{M T M}_{\mathbf{C M}}$ ) or SCS (MT $\left.\mathbf{M T S}_{\mathbf{S C S}}\right)$. In cases where the single trait likelihood profile gave evidence for 2
QTL on a single chromosome, this was tested specifically.

Variance Component Analysis. The multivariate mixed model can be written as:

$$
y=X \beta+Z u+\sum_{i=1}^{2 n q t l} W_{i} q_{\mathrm{i}}+e,
$$

where $\mathbf{y}$ is a $n \times t$ vector of observations on $t=\{1,2\}$ traits, $\mathbf{X}$ is a matrix relating records to the fixed effects, $\boldsymbol{\beta}$ is a vector of fixed effects, $\mathbf{Z}$ is a matrix relating records to individuals, $\mathbf{u}$ is a vector of additive polygenic effects, $\mathbf{W}$ is a matrix relating the record of each individual to its QTL effect, $\mathbf{q}_{i}$ is a vector of additive QTL effects corresponding to the $i$ th QTL, and $\mathbf{e}$ is a vector of residuals. The number of QTL, $n_{\mathrm{qtt}}$, is assumed equal to 1 or 2 . The random variables $\mathbf{u}, \mathbf{q}$, and $\mathbf{e}$ are assumed to be multivariate normally distributed and mutually uncorrelated. The details are reported in Lund et al. (2003).

The variance components were estimated using the average information REML algorithm (Jensen et al., 1997) implemented in the software package DMU (Madsen et al., 2006). The restricted likelihood was maximized with respect to the variance components associated with the random effects in the model. Maximizing a sequence of restricted likelihoods over a grid of specific positions yields a profile of the restricted likelihood for the QTL position. The interval for QTL was estimated by one-LOD support (Lynch and Walsh, 1998).

Identity by Descent Matrix. The identity by descent probabilities between QTL alleles of any 2 founder haplotypes are assumed to be zero; that is, founder haplotypes were unrelated (Meuwissen et al., 2002). The sire haplotypes and the paternally inherited haplotypes of the sons were used to compute the probability of inheriting the paternal or maternal allele from the sire at 
Table 2. The QTL positions and likelihood ratio test statistics (LRT) for clinical mastitis and SCS detected in variance component analyses with the combined data from 3 Nordic cattle breeds

\begin{tabular}{|c|c|c|c|c|c|c|}
\hline \multirow[b]{2}{*}{$\begin{array}{l}\text { Bos taurus } \\
\text { autosome }\end{array}$} & \multicolumn{3}{|c|}{ Clinical mastitis } & \multicolumn{3}{|c|}{ SCS } \\
\hline & $\begin{array}{l}\text { Position } \\
\quad(\mathrm{cM})\end{array}$ & LRT & $\begin{array}{l}\text { Marker } \\
\text { nearest } \\
\text { to peak }\end{array}$ & $\begin{array}{l}\text { Position } \\
\quad(\mathrm{cM})\end{array}$ & LRT & $\begin{array}{l}\text { Marker } \\
\text { nearest } \\
\text { to peak }\end{array}$ \\
\hline 9 & 72.0 & $21.2^{* * *}$ & TGLA73 & 104.0 & $12.2^{* *}$ & BMS1967 \\
\hline 11 & 25.0 & 4.0 & INRA177 & 62.0 & $11.6^{* *}$ & HELMTT44 \\
\hline 14 & 40.0 & 0.6 & - & 51.0 & $9.5^{* *}$ & BMS740 \\
\hline 18 & 58.0 & 2.9 & BMON117 & 56.5 & $14.0^{* *}$ & BMS2639 \\
\hline 29 & 3.0 & 3.7 & BM4602 & 14.0 & 3.0 & BMS1787 \\
\hline
\end{tabular}

the putative QTL, and the IBD matrix was computed using a recursive algorithm (Wang et al., 1995). The IBD matrices were computed at 2-cM intervals along the chromosome and used in the subsequent variance component estimation procedure.

Significance Level. Hypothesis tests for the presence of QTL were based on the asymptotic distribution of the likelihood ratio test (LRT) statistic, LRT = $-2 \ln \left(\mathrm{L}_{\text {reduced }}-\mathrm{L}_{\text {full }}\right)$, where $\mathrm{L}_{\text {reduced }}$ and $\mathrm{L}_{\text {full }}$ were the maximized likelihoods under the reduced and full models, respectively. For the 1-QTL model, the reduced model excluded the QTL effect being analyzed. The 2linked QTL (each affecting one of the traits) hypothesis was compared with the no-QTL hypothesis or the 1QTL (affecting 1 of the 2 traits) hypothesis. Thresholds were calculated using the method presented by Piepho (2001).

Model Selection Between Pleiotropic and Linked-QTL Models. The pleiotropic and linked-QTL models cannot be compared using likelihood ratio tests because the models are not nested. Therefore, the Bayesian information criterion (Schwarz, 1978; Kass and Raftery, 1995) was used to evaluate which model was favored. The 2 models entail the same number of parameters and consequently, the Bayesian information criterion simplifies to

$$
2 \log \left[\frac{p\left(y \mid \hat{\theta}_{\text {linkagae }} M_{\text {linkage }}\right)}{p\left(y \mid \hat{\theta}_{\text {pleiotropy }} \boldsymbol{M}_{\text {pleiotropy }}\right.}\right] .
$$

If the 2 models are assumed equally likely a priori, the result using this criterion is an approximation to the posterior probability of the pleiotropic model relative to the posterior probability of the linked QTL model (Bayes factor). Another less formal criterion used to indicate which model is more likely, is the estimated correlation between QTL effects on the 2 traits $\left(\mathbf{r}_{\mathbf{Q 1 2}}\right)$ from the pleiotropic model. The rationale behind using $\mathrm{r}_{\mathrm{Q} 12}$ is that if the 2 traits are under influence of a biallelic pleiotropic QTL, the true value of $\mathrm{r}_{\mathrm{Q} 12}$ will be 1 .

\section{RESULTS}

The QTL analyses across 3 breeds on 5 chromosomes confirmed that QTL affecting CM or SCS, or both, were segregating on BTA9, 11, 14, and 18. The QTL on BTA29 was not confirmed. The results of joint analysis of 3 breeds with a variance component method are presented in Table 2.

\section{BTA9}

Single-trait models were significant for both $\mathrm{CM}$ and SCS (Table 2). For CM, the highest peak of the likelihood ratio curve was at $72 \mathrm{cM}$ (Figure 1). The confidence interval for the position spanned from 67 to $88 \mathrm{cM}$. Within this interval, there were 2 peaks at 72 and 86 cM with LRT of 21.2 and 17.0, respectively. This suggests that there may be 2 linked QTL affecting CM. When a single-trait 2-linked QTL model for CM was run fixing 1 QTL at $72 \mathrm{cM}$, the LRT at $86 \mathrm{cM}$ was 6.6 compared with the 1-QTL model, which is suggestive but not significant. Therefore, it is possible that there are 2 QTL for CM in this region of BTA9. For SCS, the highest LRT in the single-trait model was at $104 \mathrm{cM}$, close to the marker BMS1967. Although there was some indication of an SCS QTL in the interval of the CM QTL, it did not exceed the significant threshold.

All 2-trait models were significant when compared with a model without a QTL (Table 3). The profile for the $\mathrm{MT}_{\mathrm{P}}$ model was similar to that of the $\mathrm{ST}_{\mathrm{CM}}$ and $\mathrm{MT}_{\mathrm{CM}}$ models. On the other hand, the profile for $\mathrm{MT}_{\mathrm{SCS}}$ resembled that of $\mathrm{ST}_{\mathrm{SCS}}$, and they both showed the peak at $104 \mathrm{cM}$. The $\mathrm{MT}_{\mathrm{L}}$ model had the highest LRT (25.47) with CM and SCS QTL at 72 and $104 \mathrm{cM}$, respectively. These positions were in complete agreement with the single-trait models and the $\mathrm{MT}_{\mathrm{CM}}$ and $\mathrm{MT}_{\mathrm{SCS}}$ models. The Bayes factor indicated that the linked QTL model $\left(\mathrm{MT}_{\mathrm{L}}\right)$ was 22 times more likely than the pleiotropic model $\left(\mathrm{MT}_{\mathrm{P}}\right)$, which was not a large difference. This could be because neither of the competing models was 


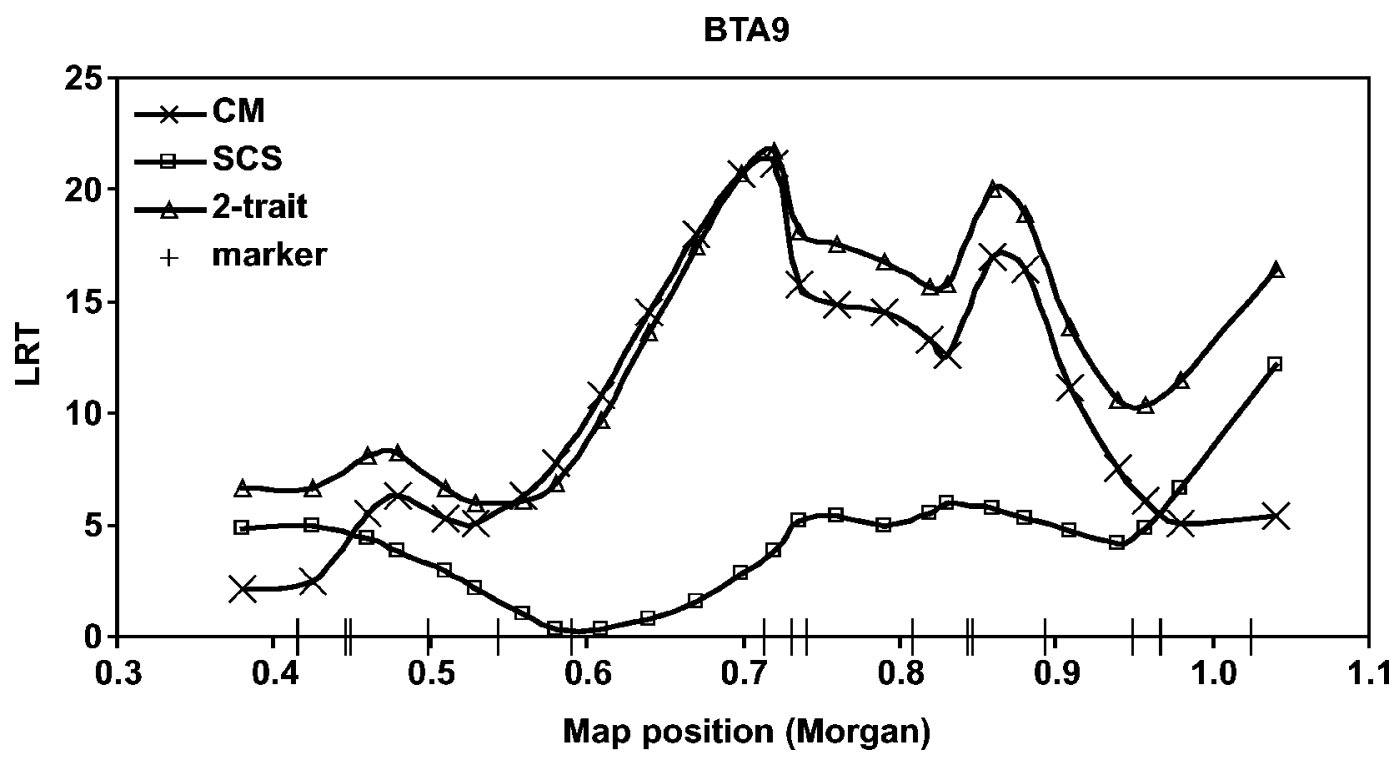

Figure 1. Likelihood profile for QTL position on Bos taurus autosome (BTA) 9 using single-trait analysis for clinical mastitis (CM) and SCS, or a 2-trait model with a pleiotropic QTL affecting both traits. LRT = likelihood ratio test.

adequate to explain the QTL variation in the region. This was supported when a more complex 2-trait model including 3 QTL was fitted. In this model, we searched for a pleiotropic QTL against a null hypothesis fitting 1 QTL at $72 \mathrm{cM}$ affecting CM and 1 QTL at $104 \mathrm{cM}$ affecting SCS. Even with this model, the LRT was around 12 in the region. It was difficult to assess the biological basis for these results, but they indicated that there was unexplained heterogeneity in the genetic model. The likely scenario is that there are at least 2 QTL in the region. The QTL around $72 \mathrm{cM}$ primarily affected CM that also affected SCS in some families, whereas the QTL around $104 \mathrm{cM}$ primarily affected SCS but also with some effect on CM in a few families.

\section{BTA11}

The single-trait analysis was significant for SCS but not for CM. The profile for the single-trait SCS analyses peaked at $62 \mathrm{cM}$ (Figure 2), but the interval was large (47 to $90 \mathrm{cM}$ ). However, there was no evidence of $2 \mathrm{QTL}$ within this interval based on a single-trait analysis for SCS with a 2-linked QTL model. The single-trait analysis for CM showed a peak at $25 \mathrm{cM}$, but the LRT did not exceed the significance threshold.

All 2-trait models were significant except for $\mathrm{MT}_{\mathrm{CM}}$. The models consistently estimated the position of an SCS QTL around $62 \mathrm{cM}$ and indicated another CM QTL around $28 \mathrm{cM}$. It is unlikely that the SCS QTL around $62 \mathrm{cM}$ affected CM. This is based on the very small increase of 0.9 between likelihoods from the $\mathrm{MT}_{\mathrm{SCS}}$ and $\mathrm{MT}_{\mathrm{P}}$ models. This is also supported by the Bayes factor, which indicated that the linkage model was 15 times more likely than the pleiotropic model.

\section{BTA14}

Single-trait analyses were significant for SCS QTL, with the highest LRT at $51 \mathrm{cM}$ in the QTL interval

Table 3. Likelihood ratio test statistics (LRT) and QTL positions for 2-trait analyses using a pleiotropic QTL model (MTP), a linked-QTL model with one QTL affecting SCS and one affecting clinical mastitis $(\mathrm{CM})\left(\mathrm{MT}_{\mathrm{L}}\right)$, and a 2-trait model in which the QTL is only affecting $\mathrm{CM}\left(\mathrm{MT}_{\mathrm{CM}}\right)$ or $\mathrm{SCS}\left(\mathrm{MT}_{\mathrm{SCS}}\right)$

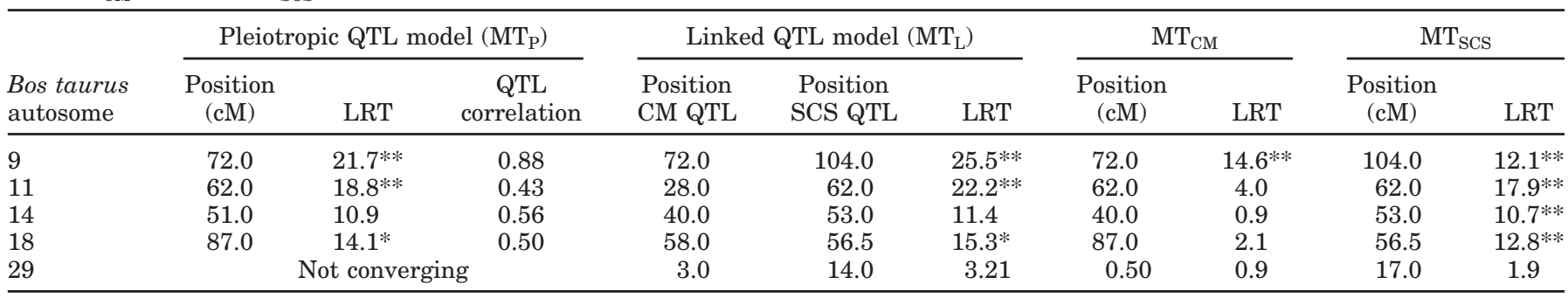

$* P \leq 0.05 ; * * P \leq 0.01$. 
BTA11

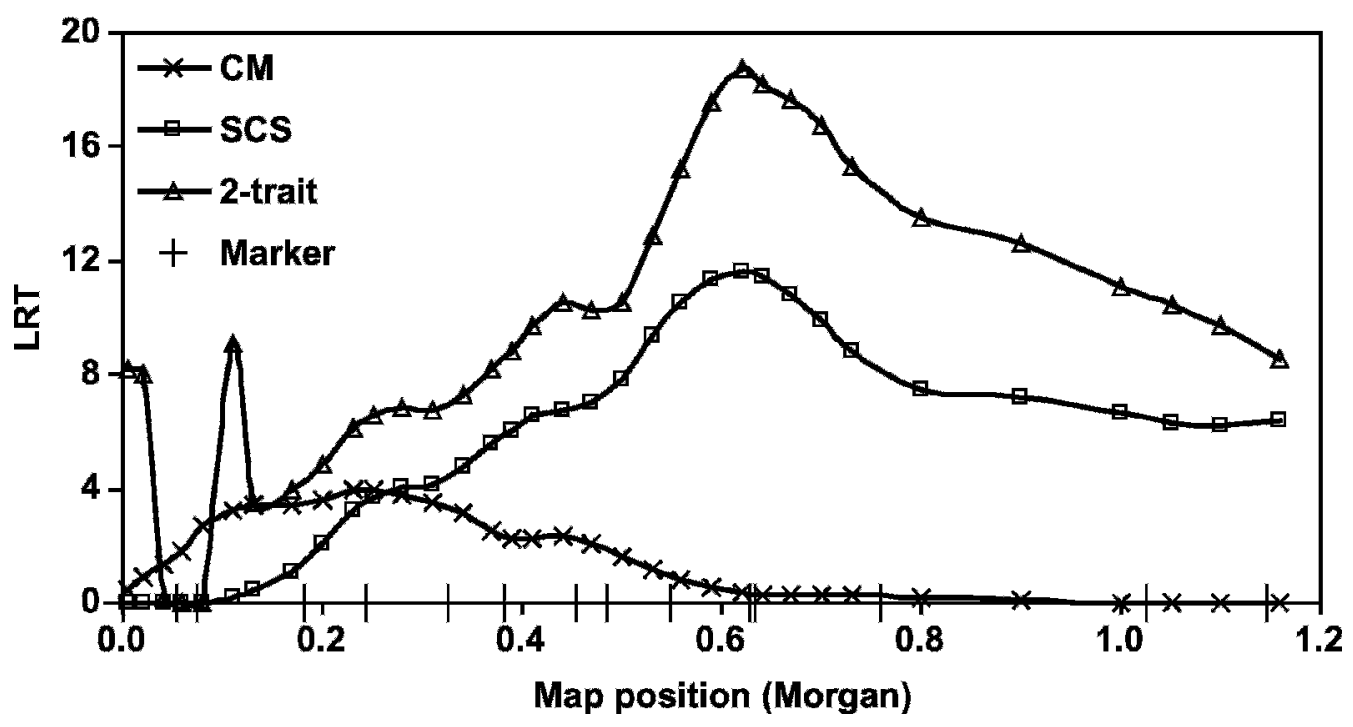

Figure 2. Likelihood profile for QTL position on Bos taurus autosome (BTA) 11 using single-trait analysis for clinical mastitis (CM) and SCS, or a 2-trait model with a pleiotropic QTL affecting both traits. LRT = likelihood ratio test.

between 35 and $53 \mathrm{cM}$ (Figure 3). The only 2-trait model that was significant was $\mathrm{MT}_{\mathrm{SCS}}$. The likelihood profile for this model resembles closely the profile of singletrait analysis for SCS as well as the pleiotropic model.

\section{BTA18}

Single-trait analyses detected a significant QTL for SCS at $56.5 \mathrm{cM}$ (interval between 30 and $87 \mathrm{cM}$ ) but none for CM (Figure 4). The QTL profiles indicated that there might be more than 1 QTL segregating on this chromosome. However, no significant evidence was found for 2 QTL for any of the traits when using models with 2-linked QTL (1 QTL fixed at $56.5 \mathrm{cM}$ ). The 2-trait models $\mathrm{MT}_{\mathrm{P}}, \mathrm{MT}_{\mathrm{L}}$, and $\mathrm{MT}_{\mathrm{SCS}}$ were all significant. However, there were only small and nonsignificant increases in the likelihoods when the QTL were allowed to affect CM. Therefore, there is most

\section{BTA14}

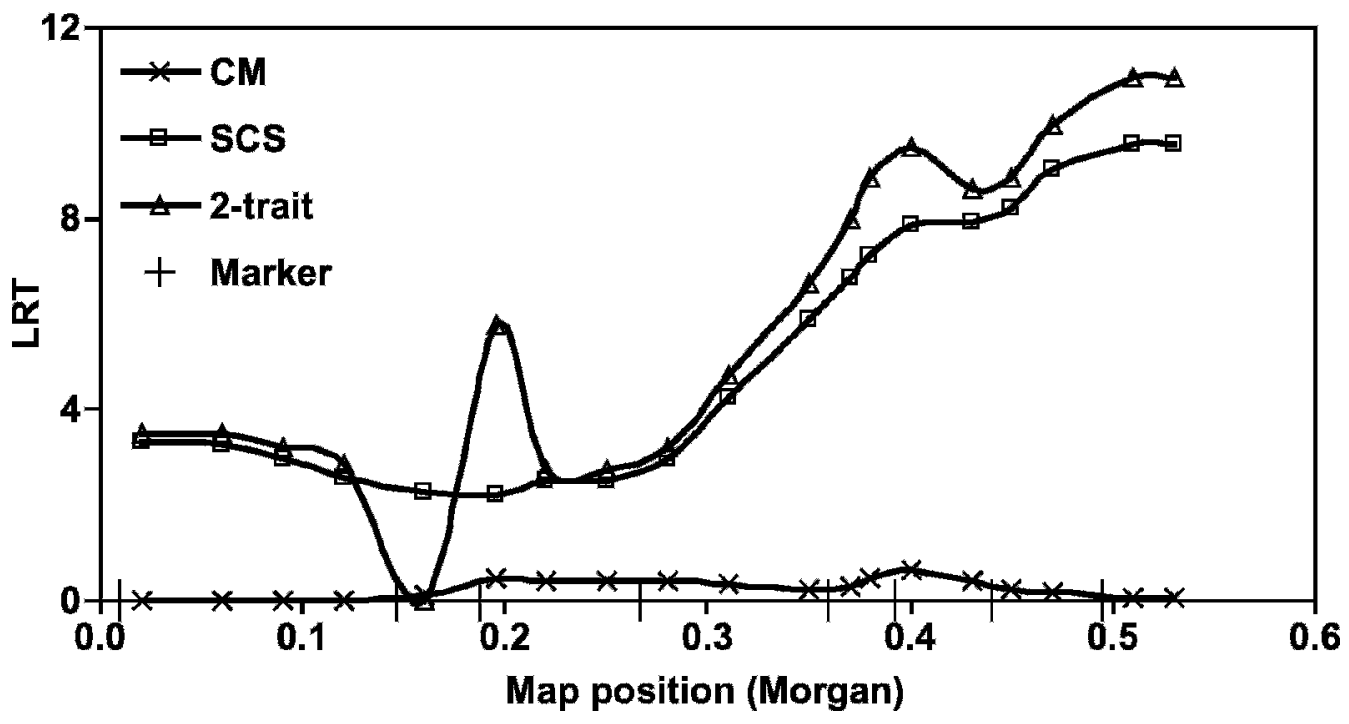

Figure 3. Likelihood profile for QTL position on Bos taurus autosome (BTA) 14 using single-trait analysis for clinical mastitis (CM) and SCS, or a 2-trait model with a pleiotropic QTL affecting both traits. LRT = likelihood ratio test. 


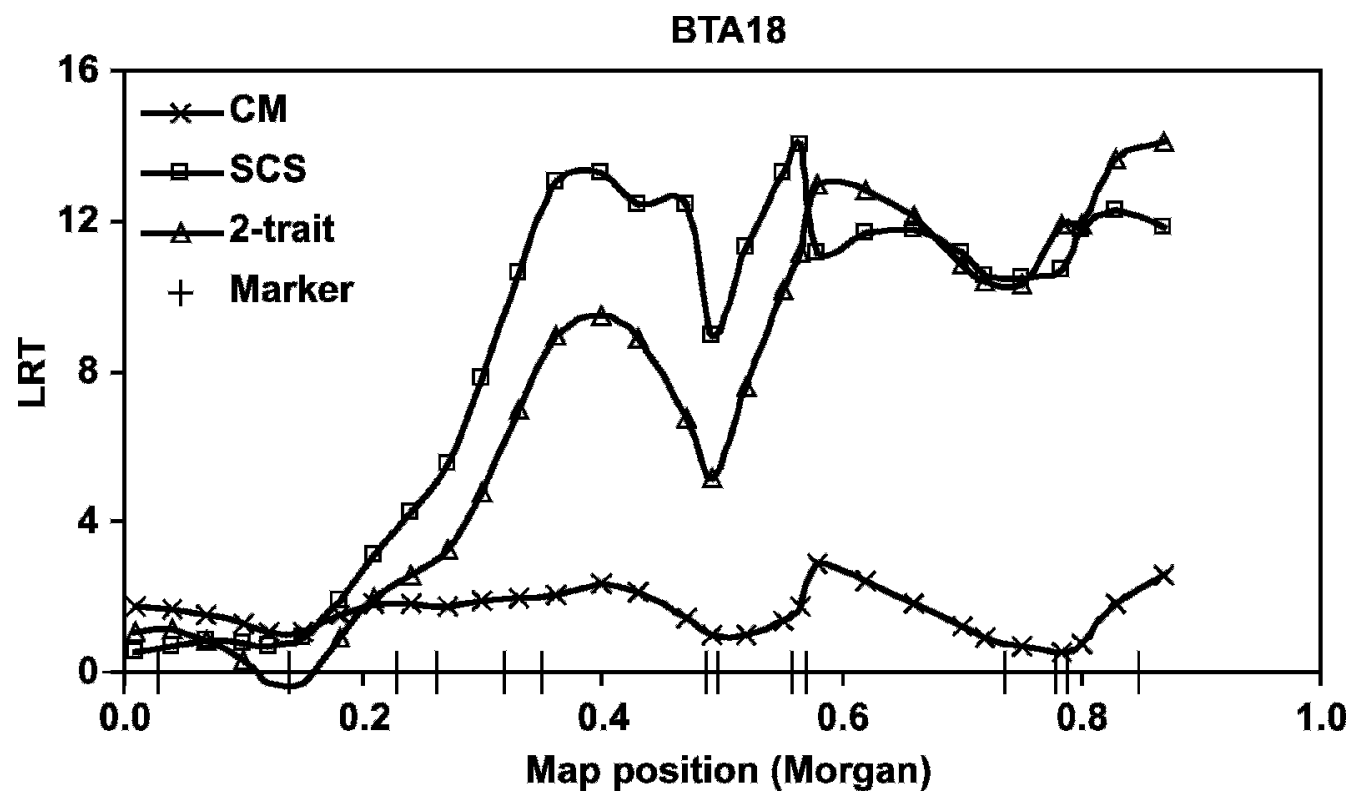

Figure 4. Likelihood profile for QTL position on Bos taurus autosome (BTA) 18 using single-trait analysis for clinical mastitis (CM) and SCS, or a 2-trait model with a pleiotropic QTL affecting both traits. LRT = likelihood ratio test.

likely only one QTL segregating on BTA18 affecting SCS.

\section{BTA29}

Neither single-trait nor 2-trait models were significant on BTA29 (Figure 5).

\section{DISCUSSION}

This joint analysis of 3 Nordic cattle breeds confirmed the presence of QTL affecting udder health related traits on 4 chromosomes. These QTL affected CM, SCS, or both, and were shown to be segregating on BTA9, 11,14 , and 18 . The QTL reported previously on BTA29 could not be confirmed.

BTA29

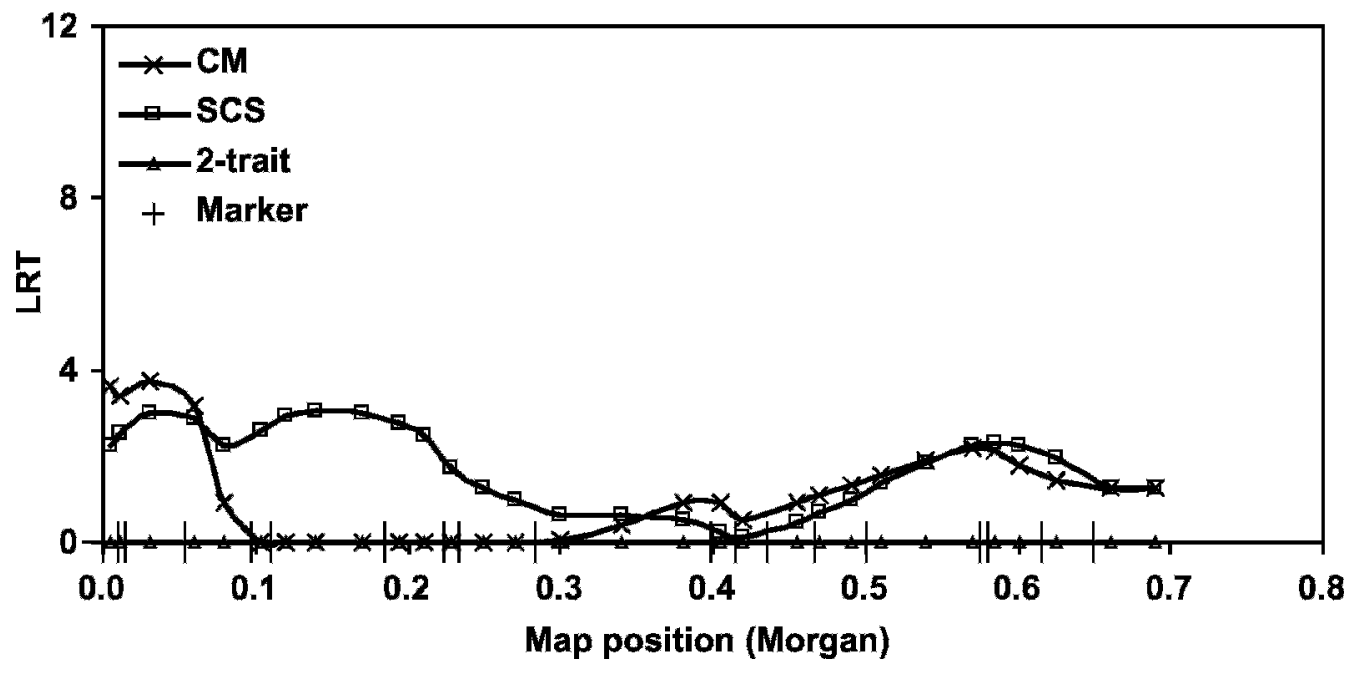

Figure 5. Likelihood profile for QTL position on Bos taurus autosome (BTA) 29 using single-trait analysis for clinical mastitis (CM) and SCS, or a 2-trait model with a pleiotropic QTL affecting both traits. LRT = likelihood ratio test. 
Our results indicated that there might be 2 linked QTL for CM on BTA9. Holmberg and AnderssonEklund (2004) reported the CM QTL on BTA9 close to marker TGLA73 in SRB, which is close to the QTL observed in this joint analysis of 3 breeds. Holmberg and Anderson-Eklund also observed the SCS QTL close to CSSM56 (41.5 cM in our map) on BTA9 in SRB. In the joint analysis of the 3 breeds, we observed 1 family segregating for a QTL at this position. However, using across-family analysis, the LRT did not exceed the significance threshold at this position. Boichard et al. (2003) also reported a QTL affecting SCS segregating on BTA9 in French dairy cattle. The QTL position was close to the marker BMS1967, which is located at the distal end of BTA9 and may be the same QTL that is identified at the distal end of BTA9 in the present study of Nordic red breeds. In our study, the data do not strongly support the hypothesis that this particular QTL affects CM.

The likelihood profile for the QTL on BTA11 for SCS showed a broad peak around $62 \mathrm{cM}$. This is in agreement with results of Holmberg and AnderssonEklund (2004) and with Schulman et al. (2004) who detected a QTL affecting SCS in SRB and FA respectively. Both reports also detected a QTL affecting CM, but at different positions on BTA11. In our study, there were no significant associations with CM on BTA11, although there was some suggestive evidence for a QTL. Out of the 21 families analyzed for this chromosome, only 3 showed significant segregation for CM in a within-family regression analysis (our unpublished data). This may not be enough for the test to be significant across all 21 families.

The present study detected a QTL affecting SCS on BTA14. This is in agreement with the results from literature in which QTL affecting SCS were detected in the studies of Schulman et al. (2004), Zhang et al. (1998) between the markers ILSTS011 and BM302, and Ashwell et al. (1997) close to the marker BM302. RodriguezZas et al. (2002) reported a QTL for SCS close to marker BM6425 (95.139 cM in the MARC map) on BTA14. However, our study did not cover this region of the chromosome. Schulman et al. (2004) also detected a QTL affecting CM on BTA14, which could not be supported by our results.

On BTA18, the present joint analysis of 3 breeds detected a QTL for SCS at the telomeric region of the chromosome, which is consistent with findings in several other studies. Ashwell et al. (1997) positioned a QTL for SCS near marker BM2078, Schulman et al. (2004) observed QTL for CM and SCS in the same region, and Xu et al. (2006) reported a QTL for SCS in the telomeric region close to TGLA227 in the German Holstein population. Kuhn et al. (2003) and Schrooten et al. (2000) also reported QTL affecting SCS on BTA18, but the position was in the middle part of the chromosome.

Several studies have reported QTL for mastitis-related traits on BTA29. Schulman et al. (2004) and Viitala et al. (2006) reported a QTL affecting SCS segregating on BTA29 close to the marker ILSTS057 in the FA population. Ashwell et al. (2004) also reported a QTL for SCS on BTA29 in the region between these markers (BMC1206-BMS1948). Although we did not detect a significant QTL on BTA29, our results showed a suggestive SCS QTL at this location in the joint analysis.

Clinical mastitis and SCS show a moderate to high genetic correlation. However, only a few families were segregating for both traits and rarely in the same location. Because the positions of QTL peaks within families were not consistent, the confidence intervals of the QTL regions remained broad even in the joint analysis. The genetic correlation between CM and SCS is $>0.70$ (Lund et al., 1999; Carlén et al., 2004; Heringstad et al., 2006); therefore, it was expected that many of the QTL affecting SCS would also affect CM. The reason why the QTL generally failed to show pleiotropic effects on SCS and CM may be because the power of detection was too low or because the 2 traits measure different aspects of udder health. Data on SCS may provide greater power to detect QTL because it is a continuous trait that is recorded objectively, whereas CM is binary data with subjective assessment that may vary among the veterinarians treating the animals. Therefore, even though CM is the primary trait of interest, we have more confidence in fine mapping those QTL that were confirmed in the joint analysis of 3 red breeds for both $\mathrm{CM}$ and SCS. On the other hand, SCS and CM are expected, in part, to measure different aspects of udder health. Mastitis in cattle is caused by many different pathogens. For example, it is becoming clear that Escherichia coli and Staphylococcus aureus result in very different immune responses (Bannerman et al., 2004). It is therefore likely that different genetic factors (different QTL) affect the susceptibility to particular pathogens. This specificity is expected to be seen in CM and SCS because $E$. coli infection often results in very acute cases of mastitis that are more likely picked up by CM than by SCS, whereas Staph. aureus infection often results in prolonged increases in SCC that may not be realized as a clinical case. The present study showed that there are QTL, especially on BTA9, that could be used for marker-assisted selection. Efficiency of selection could be increased by fine mapping the QTL, such that haplotypes that are predictive across families, and perhaps populations, could be identified. In doing so, it would be easier to find the nature of the genetic heterogeneity in the region. 


\section{ACKNOWLEDGMENTS}

This study has been partly funded by the project "New breeding tools for improving mastitis resistance in European dairy cattle," QLK5-CT2002-01186 of the EU 5th Framework Programme. We acknowledge the Nordic breeding organizations FABA Breeding (Helsinki, Finland), Svensk Avel (Skara, Sweden), and Dansire (Assentoft, Denmark) for providing the material for the study.

\section{REFERENCES}

Ashwell, M. S., D. W. Heyen, T. S. Sonstegard, C. P. Van Tassell, Y. Da, P. M. VanRaden, M. Ron, J. I. Weller, and H. A. Lewin. 2004. Detection of quantitative trait loci affecting milk production, health, and reproductive traits in Holstein cattle J. Dairy Sci. 87:468-475.

Ashwell, M. S., C. E. Rexroad, R. H. Miller, P. M. Vanraden, and Y. Da. 1997. Detection of loci affecting milk production and health traits in an elite US Holstein population using microsatellite markers. Anim. Genet. 28:216-222.

Bannerman, D. D., M. J. Paape, J.-W. Lee, X. Zhao, J. C. Hope, and P. Rainard. 2004. Escherichia coli and Staphylococcus aureus elicit differential innate immune response following intramammary infection. Clin. Diagn. Lab. Immunol. 11:463-472.

Boichard, D., C. Grohs, F. Bourgeois, F. Cerqueira, R. Faugeras, A. Neau, R. Rupp, Y. Amigues, M. Y. Boscher, and H. Leveziel. 2003. Detection of genes influencing economic traits in three French dairy cattle breeds. Genet. Sel. Evol. 35:77-101.

Carlén, E., E. Strandberg, and A. Roth. 2004. Genetic parameters for clinical mastitis, somatic cell score, and production in the first three lactations of Swedish Holstein cows. J. Dairy Sci. 87:3062-3070.

Hansen, M., M. S. Lund, M. K. Sorensen, and L. G. Christensen. 2002. Genetic parameters of dairy character, protein yield, clinical mastitis, and other diseases in Danish Holstein cattle. J. Dairy Sci. 85:445-452.

Heringstad, B., D. Gianola, Y. M. Chang, J. Odegard, and G. Klemetsdal. 2006. Genetic associations between clinical mastitis and somatic cell score in early first-lactation cows. J. Dairy Sci. 89:2236-2244.

Heringstad, B., G. Klemetsdal, and J. Ruane. 2000. Selection for mastitis in dairy cattle: A review with focus on the situation of the Nordic countries. Livest. Prod. Sci. 64:95-106.

Holmberg, M., and L. Andersson-Eklund. 2004. Quantitative trait loci affecting health traits in Swedish dairy cattle. J. Dairy Sci. 87:2653-2659.

Green, E., K. Falls, and S. Crooks. 1990. Documentation for CRI-MAP, version 2.4. Washington University, St. Louis, MO.

Jensen, J., E. Mantysaari, P. Madsen, and R. Thompson. 1997. Residual maximum likelihood estimation of (co)variance components in multivariate mixed linear models using average information. J. Indian Soc. Agric. Stat. 49:215-236.

Jiang, C., and Z. B. Zeng. 1995. Multiple trait analysis of genetic mapping for quantitative trait loci. Genetics 140:1111-1127.

Kass, R. E., and A. E. Raftery. 1995. Bayes factors. J. Am. Stat. Assoc. 90:773-795.

Klungland, H., A. Sabry, B. Heringstad, H. G. Olsen, L. Gomez-Raya, D. I. Vage, I. Olsaker, J. Odegard, G. Klemetsdal, N. Schulman, J. Vilkki, J. Ruane, M. Aasland, K. Ronningen, and S. Lien. 2001. Quantitative trait loci affecting clinical mastitis and somatic cell count in dairy cattle. Mamm. Genome 12:837-842.

Knott, S. A., and C. S. Haley. 2000. Multitrait least squares for quantitative trait loci detection. Genetics 156:899-911.
Kuhn, Ch., J. Bennewitz, N. Reinsch, N. Xu, H. Thomsen, C. Looft, G. A. Brockmann, M. Schwerin, C. Weimann, S. Hiendleder, G. Erhardt, I. Medjugorac, M. Forster, B. Brenig, F. Reinhardt, R. Reents, I. Russ, G. Averdunk, J. Blumel, and E. Kalm. 2003. Quantitative trait loci mapping of functional traits in the German Holstein cattle population. J. Dairy Sci. 86:360-368.

Lund, M. S., J. Jensen, and P. H. Petersen. 1999. Estimation of genetic and phenotypic parameters for clinical mastitis, somatic cell production deviance, and protein yield in dairy cattle using Gibbs sampling. J. Dairy Sci. 82:1045-1051.

Lund, M. S., P. Sørensen, B. Guldbrandtsen, and D. A. Sorensen. 2003. Multitrait fine mapping of quantitative trait loci using combined linkage disequilibria and linkage analysis. Genetics 163:405-410.

Lynch, M., and B. Walsh. 1998. Genetics and Analysis of Quantitative traits. Sinauer Associates, Inc., Sunderland, MA.

Madsen, P., P. Sørensen, G. Su, L. H. Damgaard, H. Thomsen, and R. Labouriau. 2006. DMU-A package for analyzing multivariate mixed models. 8th World Congr. Genet. Appl. Livest. Prod., Belo Horizonte, Brazil. CD-ROM Commun. 27-11.

Meuwissen, T. H. E., A. Karlsen, S. Lien, I. Olsaker, and M. E. Goddard. 2002. Fine mapping of a quantitative trait locus for twinning rate using combined linkage and linkage disequilibrium mapping. Genetics 161:373-379.

Piepho, H. P. 2001. A quick method for computing approximate thresholds for quantitative trait loci detection. Genetics 157:425-432.

Pösö, J., and A. E. Mäntysaari. 1996. Relationship between clinical mastitis, somatic cell score, and production for first three lactations of Finnish Ayrshire. J. Dairy Sci. 79:1284-1291.

Rodriguez-Zas, S. L., B. R. Southey, D. W. Heyen, and H. A. Lewin. 2002. Detection of quantitative trait loci influencing dairy traits using a model for longitudinal data. J. Dairy Sci. 85:2681-2691.

Rupp, R., and D. Boichard. 2003. Genetics of resistance to mastitis in dairy cattle. Vet. Res. 34:671-688.

Schrooten, C., H. Bovenhuis, W. Coppieters, and J. A. M. VanArendonk. 2000. Whole genome scan to detect quantitative trait loci for conformation and functional traits in dairy cattle. J. Dairy Sci. 83:795-806.

Schulman, N. F., S. M. Viitala, D. J. De Koning, J. Virta, A. MakiTanila, and J. H. Vilkki. 2004. Quantitative trait loci for health traits in Finnish Ayrshire cattle. J. Dairy Sci. 87:443-449.

Schwarz, G. 1978. Estimating the dimensions of a model. Ann. Statist. 6:461-464.

Sørensen, P., M. S. Lund, B. Guldbrandtsen, J. Jensen, and D. Sorensen. 2003. A comparison of bivariate and univariate QTL mapping in livestock populations. Genet. Sel. Evol. 35:605-622.

Strandberg, E., and G. E. Shook. 1989. Genetic and economic responses to breeding programs that consider mastitis. J. Dairy Sci. 72:2136-2142.

Viitala, S., J. Szyda, S. Blott, N. Schulman, M. Lidauer, A. MakiTanila, M. Georges, and J. Vilkki. 2006. The role of bovine growth hormone receptors and prolactin receptor genes in milk, fat and protein production in Finnish Ayrshire cattle. Genetics 173:2151-2164.

Wang, T., R. L. Fernando, S. Van der Beek, and M. Grossman. 1995. Covariance between relatives for a marked quantitative trait locus. Genet. Sel. Evol. 27:251-274.

Xu, N. Y., S. Paul, J. Bennewitz, N. Reinsch, G. Thaller, F. Reinhard, C. Kuhn, M. Schwerin, G. Erhardt, C. Weimann, H. Thomsen, S. Mishra, and E. Kalm. 2006. Confirmation of quantitative trait loci for somatic cell score on bovine chromosome 18 in the German Holstein. Arch. Tierzucht. 49:111-119.

Zhang, Q., D. Boichard, I. Hoeschele, C. Ernst, A. Eggen, B. Murkve, M. Pfister-Genskow, L. A. Witte, F. E. Grignola, P. Uimari, G. Thaller, and M. D. Bishop. 1998. Mapping quantitative trait loci for milk production and health of dairy cattle in a large outbred pedigree. Genetics 149:1959-1973. 